\title{
Considerações Geológicas e Sobre o Parque Produtor de Rochas Ornamentais no Município de Santo Antônio de Pádua-RJ
}

\author{
João Baptista Filho ${ }^{1}$ \& Maira Damião Tanaka² \\ (1) Departamento de Geologia - I. Geociências / UFRJ - Universidade Federal do Rio de Janeiro, \\ Instituto de Geociências, Ilha do Fundão, 21949-900 - Rio de Janeiro - RJ, Brasil
}

(2) $D R M-R J$

\section{Resumo}

A extração e o beneficiamento de Rochas Ornamentais no Município de Santo Antônio de Pádua (RJ), vem registrando um considerável crescimento à partir da década de 90. Este trabalho é uma tentativa de delinear a forma como esta industrialização vem ocorrendo e a atual dependência da economia local com esta atividade.

Palavras-chave: rochas ornamentais, Santo Antônio de Pádua

\begin{abstract}
This paper is an attempt to delineate the ways of nowadays industrialization of ornamental Rocks in Santo Antônio de Pádua (RJ)

It is very important to emphasize the almost total dependence of the local economy with this kind of activity.

Key-words: ornamental rocks, Santo Antônio de Pádua
\end{abstract}

\section{Introdução}

O município de Santo Antônio de Pádua, situada no Noroeste do estado, do Rio de Janeiro, vem chamando a atenção por sua atividade mineral, relativa à granitos ornamentais, principalmente na década de 90; quando desde então, vem registrando um crescimento considerável no setor.

Atualmente, aproximadamente, uma década após o início da legalização e profissionalização daquelas atividades, que até então vinham sendo realizadas de forma amadora, sem qualquer orientação técnica, observamos uma nova realidade: o início de um processo de industrialização que já se faz sentir em algumas empresas.

Através deste trabalho, tentamos delinear a forma como esta industrialização vem ocorrendo; e quantificar a atual dependência da economia local com relação à atividade mineira de extração e beneficiamento de "rochas ornamentais". 


\section{Município de Santo Antônio de Pádua}

\subsection{Localização}

O município de Santo Antônio de Pádua, localiza-se na Região Norte Fluminense, no Estado do Rio de Janeiro.

Abrange uma área total de 615,2 km², e sua sede apresenta coordenadas geográficas $21^{\circ} 30^{\prime} 30^{\prime}$ 'S , e $42^{\circ} 11^{\prime} 00^{\prime}$ W, altitute média de $930 \mathrm{~m}$, e distanciando $256 \mathrm{~km}$ da cidade do Rio de Janeiro, cidade sede de nossos trabalhos.

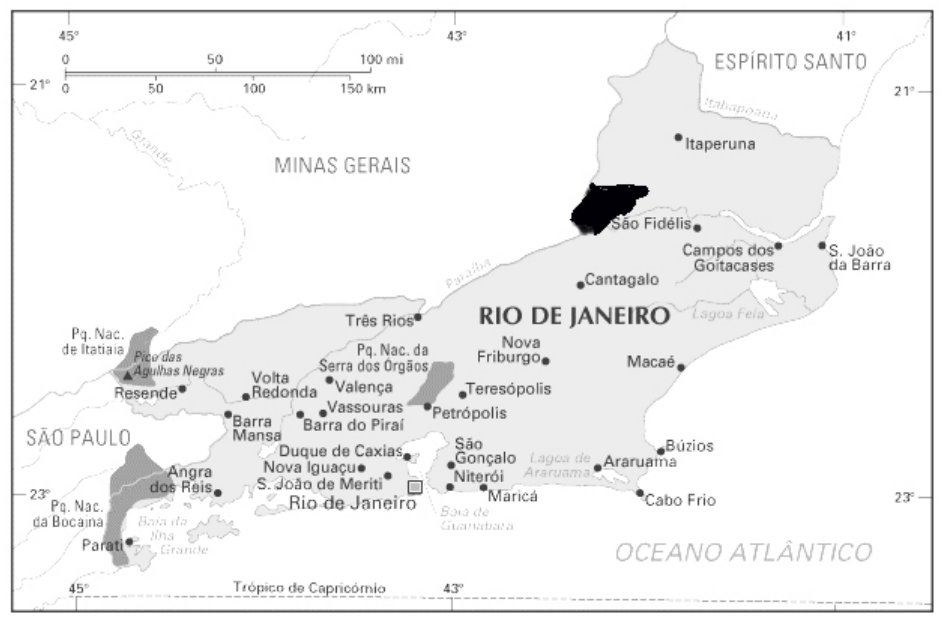

Figura 1 Mapa de Localização. Em destaque encontra-se o município no qual foram desenvolvidos nossos trabalhos

\section{Geologia Regional}

A geologia da região foi classificada segundo Brandalise et alli (CPRM, 1976) , como sendo um complexo denominado “Associação Paraíba do Sul”

Segundo o autor, essa Associação poderia ser subdividida em diversas litologias e dois complexos:

a) principais litologias

- gnaisses

- rochas carbonáticas (mármores)

- quartzitos

- xistos

- anfibolitos 
b) Complexos

- Charnockitico

- Migmatítico

\subsection{Descrição Litológica Sumária:}

\section{Gnaisses}

São as principais rochas dessa unidade, em geral constituem-se como encaixantes.

Apresentam-se com bandamentos bastantes expressivos, definidos pela alternância de padrões claros e escuros, podendo variar quanto à espessura.

Segundo a estrutura desses gnaisses, podem ser individualizados e classificados, três tipos litológicos:

\section{a) biotita - gnaisse}

Apresentam um bandamento, com espessura variando de milimétros a centimétricas $(40 \mathrm{~cm})$.

Suas porções claras são constituídas de quartzo, plagioclásio e microclina: e as camadas mais escuras constituídas de biotita e anfibólio.

Podem ser granatíferos ou não; e sua granulometria pode variar de fina, média até grosseira.

\section{b) biotita - gnaisse porfiroblástico}

Apresentam porfiroblástos e porfiroclástos de feldspato branco ou róseo, alongados segundo a direção de foliação.

Ocorrem em zonas no interior do gnaisse acima, descrito num trecho que vai do vale do Rio Paraíba do Sul até a Serra do Mar.

\section{c) gnaisses das faixas cataclásticas}

Apresentam um aspecto fitado com leitos biotíticos com espessura mínima se comparado às camadas quartzo-feldspáticas (de até $4 \mathrm{~cm}$ ). A granulometria é fina à média, exceção às faixas miloníticas (CPRM, 1976).

\section{Quartzitos}

Os quartzitos ocorrem como mega-lentes, em geral encaixados em rochas xistosas e biotita- gnaisses; Acompanhando essas mega-lentes, via de regra, ocorrem porções xistosas e micáceas diferenciadas. 
Apresentam uma granulometria geralmente grosseira podendo também, ocorrer tipos mais finos cujas colaboração varia de bege à branca. A sua principal mineralogia consta de quartzo,subordinadamente feldspato e sillimanita, podendo por vezes apresentar biotita e muscovita.

Estruturalmente, são comuns encontrar dobras, fraturas e clivagens neste tipo litológico.

Por serem mais recentes do que as encaixantes, em geral formam um relevo típico de serras

\section{Rochas Carbonáticas}

Assim como os quartzitos, são encontradas nas formas de lentes e mega-lentes encaixadas em gnaisses e/ou associadas à rochas anfibolíticas que passam gradualmente à uma gnaisse anfibolítico e novamente ao gnaisse.

Essas porções carbonáticas, são constituídas de mármores dolomíticos e mármores calcíticos, intercalados com rochas calcisilicáticas.

\section{Complexos Charnockítico}

Este complexo é litologicamente, constituído por:
a) charnockitos
b) granulitos
c) hornblenda - biotita gnaisse
d) metagabros
e) metadioritos
f) anfibolitos

As duas primeiras litologias são as principais constituintes desse complexo, as demais ocorrem secundariamente. 
Os charnockitos encontram-se em faixas metamórficas correspondentes às fáceis granulito à granulitos - anfibolitico.

Mineralogicamente, são compostas por quartzo, plagioclásio, hiperstênio, ortoclásio, hornblenda verde ,biotita e augita como minerais essenciais; Ocorrem ainda,granada e pigeonita.

\section{Complexos Migmáticos}

Entre complexos,possuem tipos litológicos representados por:
a) metatexitos
b) diatexitos

Em comum esta rochas representam uma composição quartzo - feldspática que é acrescida às feições da rocha originalmente metamórfica, seja na forma de pegmatitos, seja na forma de lentes ou de leitos de material quartzo - feldspático.

Nos metatexitos observa-se como aspecto geral, a textura de rochas migmatitizadas, porém com a presença de alguns porfirtoblástos (normalmente de feldspato).

Esses migmatitos apresentam-se com estruturas estromáticas. Os leucossomas são constituídos de faixas quartzo- feldspáticas de granulação média à grosseira, que podem apresentar porfiroblastos de feldspatos. Os melanossomas são constituídos de faixas ricas em biotita de granulação fina à média, contendo também quartzo, feldspato , piroxênio e/ou anfibolio e granada (CPRM, 1976).

Os diatexitos também denominados de gnaisse-granitóide ou diatexito “granitóide”, ocorrem, em geral, como lentes ou núcleos inclusive no interior dos metatexitos, sua granulometria costuma variar de média à grosseira. São comuns a presença de veios de quartzo, veios aplíticos , porções graníticas e diques de rochas básicas, cortando a presente litologia. Chama-se a atenção ainda, para a presença de núcleos anfibolíticos e "bolsões” de rocha carbonáticas no interior dessses diatexitos. 


\subsection{Geologia Estrutural}

As principais estruturas estão relacionadas ao Sinforme Santa Maria Madalena; caracterizado por um dobramento apertado, ou dobra de deslizamento, com eixo horizontal na direção $\mathrm{N} 40^{\circ}-50^{\circ} \mathrm{E}$ (direção peferencial da foliação). A aba Noroeste apresenta como atitude, $\mathrm{N} 46^{\circ} / 68^{\circ} \mathrm{SE}$.

Ocorrem ainda, fraturas de direção quase perpendicular ao eixo da Sinforme, $\mathrm{N} 45^{\circ} \mathrm{W}$.

\subsection{Geologia local}

A geologia local , corresponde à área mapeada por Oliveira, 1998. Embora não cubra a totalidade do município, abrangendo apenas $66,0 \mathrm{~km}^{2}$. Constitui-se o mais recente e detalhado trabalho de mapeamento geológico realizado na região, e inclui a principal região de extração de rochas ornamentais.

\subsubsection{Geologia da Serra do Bonfim}

A área é representada por uma sequência de rochas conhecidas como associação Paraíba do Sul e suas sub-divisões ( Complexo Charnockitico e Migmatítico ), representados por: quartzo-feldspato-biotita-gnaisses milonitizados; gnaisses bandados; gnaisses quartzo-feldspáticos milonitizados, charnockitos e gnaisses granitóides.

\section{Gnaisses Milonitizados}

Ocorrem principalmente ao longo da Serra do Bonfim. Trata-se de gnaisses de composição granítica que sofreram processo de milonitização. A minerologia principal é constituída por quartzo feldspato-biotita (hornblenda); apresenta uma granulometria fina à média, com porfiroblastos e porfiroclastos de feldspato de até $0,5 \mathrm{~cm}$, e rico em quartzo, estando este em forma de fitas, devido ao intenso processo de deformação sofrido pelas rochas em virtude dos falhamento regionais. 
Este gnaisse apresenta variações litológicas ao longo da Serra do Bonfim que dão origem a três tipos comercializados:

1) “Granito olho-de-pompo” - rocha de granulação média com porfiroclástos de ortoclásio branco.

2) “Granito pinta- rosa” - rocha de granulação média com porfiroclástos de ortoclásio rosa.

3) “Granito fino” - rocha de granulação fina com ortoclásio branco.

A delimitação dos três tipos de “granitos” não pode ser definido devido à escala de trabalho utilizada. Ocorrem em faixas descontínuas podendo se apresentar ora com espessuras bem reduzadas (até 1,0m), ora com algumas dezenas de metros

O gnaisses apresentam uma foliação bem definida com atitude constante N44 $\mathrm{E} / 65^{\circ} \mathrm{SE}$ ao longo serra e fraturas de atitudes $\mathrm{N} 40^{\circ} \mathrm{W} / 50^{\circ} \mathrm{NE}$.

\section{Gnaisses bandados}

Ocorrem entre a Serra do Bonfim e a Serra da Pedra Bonita. Os poucos afloramentos observados, encontravam-se em estado bastante alterado. A dificuldade em se encontrar afloramentos está ligada à espessura de solo, nunca menor que 6,0m.

Semelhante aos gnaisses miloníticos, apresentam uma foliação bastante constante $\mathrm{N} 40^{\circ}-50^{\circ} \mathrm{E} / 70^{\circ} \mathrm{SE}$. Concordantes com esta, foram encontrados quartzitos e bandas de quartzo com até $15 \mathrm{~cm}$ de espessura.

O contato do gnaisse bandado, com as rochas da Serra do Bonfim e Pedra Bonita, é feito através de uma falha ou zona de falhamento inferida por foto-interpretação.

\section{Gnaisses quartzo-fesdspáticos milonitizados com lentes de quartzito}

Constituem-se de quartzo e feldspato com presença discreta de biotita e anfibólio. Assim como as rochas da Serra do Bonfim, encontram-se bastante milonitizadas 
e com atitudes relativamente constante $\mathrm{N} 40^{\circ} \mathrm{E} / 60^{\circ} \mathrm{SE}$, apresentando as mesmas cacterísticas de desplacamento como os encontrados nos "granitos” da Serra do Bonfim, sendo igualmente explorado comercialmente.

As variações de cores dessa litologia devido as alterações, originam três tipos comercializados:

\section{1) "Pedra madeira branca" \\ 2) “Pedra madeira amarela” \\ 3) “Pedra madeira rosa”}

\section{Charnockito}

São encontrados principalmente na Serra da Pedra Bonita. Próximo à Faz. Rochedo, muitos matacões aflorantes com volumes de até $120 \mathrm{~m}^{3}$, apresentamumacorverde de tonalidade escura.

Mineralógicamente observa-se a presença de quartzo estando o mesmo na forma de grãos ou estirados. A biotita está em quantidade discreta. Os feldspatos, além da cor marcante, apresentam geminação Carlsbad. O piroxênio presente chega ao tamanho de 2,0cm, em forma prismática. Alguns blocos quando alterados lembram o gnaisse facoidal do município do Rio de Janeiro, sendo estes localizados em um córrego próximo ao colégio Fazenda da Cachoeira.

Os afloramentos encontrados, apresentam uma atitude $\mathrm{N} 40^{\circ} \mathrm{E} / 65^{\circ} \mathrm{SE}$, mostram-se milonitizados, com granulometria fina e estão presentes também em alguns pontos da Serra do Bonfim.

\section{Gnaisse- Granitóide}

Ocorrem como corpos individualizados na extremidade Sudoeste da Serra da Pedra Bonita.

Constitui-se principalmente de quartzo e feldspato, com algumas pontuações negras formadas por biotita e anfibólio, os quais formam um lineamento muito sutil na rocha. A granulometria varia de média a grossa . 


\section{Parque Produtor}

\subsection{Histórico}

Santo Antônio de Pádua, apresenta uma história semelhante a de tantas outras cidades localizadas na região.

Com dois ciclos bem definidos, alternando momentos de extrema riqueza, apontando a região como referência econômica, social e cultural e a momentos de extrema miséria ligados a uma estagnação econômica.

Durante o correr dos anos o município passou por dois ciclos principais:

\subsection{Os Ciclos Agropecuários}

Dentre alguns desses ciclos destacam-se os:
a) cana- de-açúcar
b) café
c) arroz
d) pecuária leiteira extensiva

\subsection{Ciclo Mineiro}

As atividades minerais com relação à exploração de rochas ornamentais na região de Santo Antônio de Pádua, iniciou-se na década de 60, quando alguns pequenos produtores rurais começaram a utilizar uma “pedra”facilmente “desplacável” (friável) para revestir o piso de currais. Origina-se daí, uma das nomenclaturas utilizadas ainda hoje por pessoas da região: “pedra curral”. Tal "pedra” era simplesmente retirada dos afloramentos, desplacada e assentada diretamente sobre os pisos.

Ao final da década de 70, início de 80, moradores locais começaram a serrá-la e empregá-la na construção civil, como revestimento para muros, pisos e jardins em substituição aos similares encontrados no mercado, tendo como principal atrativo, os preços mais acessíveis. 
A partir de então, a rocha ornamental começa a ser diferenciada e comercializada recebendo diversos nomes de acordo com suas características principalmente aquelas relacionadas à cor e aparência: “ pedra Miracema "/ "pedra Paduana”, "pedra olho de pombo", "pedra madeira amarela”, pedra madeira vermelha” etc... Esta nomenclatura persiste até os dias de hoje com algumas modificações.

\section{Aspectos Econômicos}

A economia com base na extração mineral de Santo Antônio de Pádua, vem se desenvolvendo muito rapidamente na última década.

Até o momento o desenvolvimento vinha ocorrendo de forma relativamente homogênea através de uma extração e beneficiamento praticamente artesanal, onde os principais fatores diferenciadores eram os tamanhos das propriedades, uma vez que, inicialmente tudo girava em função somente do direito de propriedade da terra e o número de serras que o proprietário conseguiria manter, através da extração em suas pedreiras; ou pela compra de blocos de pedreiras menores.

Devia-se esse cenário, ao fato de que, até o ano de 1994/1996, a maioria das atuais empresas não apresentavam qualquer registro, ou seja, não existiam perante qualquer orgão público regulamentador. Somente a partir desta data, sob a orientação do DRM, numa ação pioneira na região, vem se desenvolvendo um trabalho caracterizado pela disponibilidade e acessibilidade de entendimento , ensinamento e acompanhamento das atividades locais. Foi iniciado um novo ciclo na produção mineral.

Este novo rumo dentro do ciclo mineiro, teve como ponto de partida a legalização das atividades de mineração que até então vinham sendo desenvolvidas de forma ilegal; o que de certa maneira, caracterizou a mudança de uma economia familiar, para o início de uma economia que atualmente começa a despontar para o caminho de uma verdadeira industrialização

\subsection{Empresas Caracterizadas Segundo a Extração}

a) O proprietário do terreno extrai as rochas - O dono da propriedade extrai todo o minério numa frente única. O responsável legal e o responsável pela exploração 
é o próprio, auxiliado por um geólogo ou engenheiro de minas que cuida da parte inicial de legalização e assessoria técnica.

b) O Proprietário do terreno é o titular do registro porém aloca parte ou integralmente a frente de lavra - O proprietário da terra divide uma única frente de lavra em várias frente menores; uma espécie de alocação, num sistema que em geral é de $1 / 4$ da renda para o proprietário e 3/4 para o explorador. Embora a extração nas frentes de lavras sejam “alocadas”, o responsável legal pela exploração é o proprietário, cabendo aos locatários seguirem as especificações técnicas estabelecidas pelos geólogos ou engenheiros de minas nos devidos processos de legalização.

c) O proprietário aloca integralmente a área onde se desenvolve a mineração Neste caso, o titular da legalização mineral é o próprio empreendedor; cabendo ao mesmo todas as responsabilidades legais e ambientais do processo de extração; e ao dono do terreno, receber uma cota que varia de 20-25\% (podendo extraordinariamente, chegar a $30 \%)$.

É importante notar que, anteriormente, um problema muito comum nessas relações, era quanto à responsabilidade em relação à degradação e recuperação ambiental, pois devido a falta de orientações técnicas adequadas, tanto do ponto de vista da colocação do rejeito da extração propriamente dita, quanto da responsabilidade jurídica, os litígios entre as partes envolvidas é muitas vezes entre proprietários de terras e moradores vizinhos à mineração eram constantes.

Com o processo de legalização e o desenvolvimento do caráter realmente empresarial por parte dos empreendedores, tais conflitos tem se tornados cada vez mais raros.

\subsection{Modelos Recentes}

Atualmente, podemos identificar outras formas de relações entre donos de terras, empreendedores e empreendimentos.

a) “Terceirização” - O dono da terra , é o responsável legal pela mineração perante os órgãos, oficiais e o próprio responsável pela frente de lavra, porém contrata 
o serviço de “empresas” (constituídas ) que “prestam um serviço de extração “. De fato, o que ocorre é uma transferência da responsabilidade sobre os encargos trabalhistas.

b) “Prestação de Serviço” - No caso observado, constituía-se uma firma onde parte dos empregados e empregadores eram membros da mesma família e/ou amigos, com a existência de somente alguns poucos empregados sem qualquer vínculos familiares ou afetivos.

\subsection{Empresas Caracterizadas Segundo o Beneficiamento}

Até o final da década de 90, o beneficiamento pelos quais as rochas passavam, eram bastante simples, constava basicamente de uma serragem manual, realizada numa serra desenvolvida e produzida por uma (e única) indústria de máquinas do município.

A serra utilizada no beneficiamento, consta de um disco diamantado movido por um motor elétrico de $15 \mathrm{Hp}$ de potência e resfriado a água. (somente os discos diamantados são produzidos e comprados de outras localidades industriais).

\subsubsection{O Beneficiamento}

Podemos dividir as rochas produzidas na região em dois grupos comerciais: Pedra Miracema/ Paduana e Pedra Madeira.

a) Pedra Miracema/ Paduana - Por serem mais rígidas, podem ser retiradas da frente de lavra em blocos de dimensões maiores e mais padronizadas do que as do tipo pedra Madeira.

Nas pedreiras, são produzidos blocos de dimensões aproximadas de 50x50x40cm que posteriormente são desplacadas em lajes “brutas” de 50x50x4cm. Em seguida, essas lajes brutas são encaminhadas às serrarias para um beneficiamento final, sendo cortadas em lajes menores de dimensões aproximadamente $11,5 \times 23,0 \times 4,0 \mathrm{~cm}$, chamadas de “bloquinhos”; posteriormente,esses “bloquinhos”são rachados por percussão manual com a utilização de espátulas metálicas e uma pequena marreta( ver fluxograma). 
b) Pedra madeira - As rochas do tipo Pedra Madeira, apresentam-se mais friáveis, seus afloramentos encontram-se mais alterados e as perdas são maiores do que as ocorridas com as pedras Miracema, desta forma, torna-se mais difícil se obter blocos com as dimensões citadas acima.

Sendo assim, muitas vezes, os blocos que saem das pedreiras para as serrarias e o beneficiamento final, apresentam dimensões menores do que as obtidas para as pedras Miracema.

Chama-se a atenção, que além da escassez de afloramentos, essas rochas apresentam grandes perdas em todas as etapas do processo, da extração ao assentamento final, passando pelo beneficiamento e transporte, o que ocasiona uma perda por volume muito maior do que o ocorrido com a pedra Miracema/Paduana.

\subsection{Os Primeiros Modelos}

a) Modelo Familiar - em geral, era feito de maneira informal, literalmente de "fundo" ou "frente"de quintal, utilizando-se da mão-de-obra familiar, com todos, desde avós até netos trabalhando no desplacamento das pedras.

Os homens, trabalham nas serras do próprio núcleo familiar ou muitas vezes, nas frentes de lavra, como forma de renda mais fixa.

Algumas dessas “cooperativas “ familiares, constituem-se grande parte das aproximadamente 100 serrarias cadastradas na prefeitura como “empresa de pedra”.Essas empresas no geral possuem uma ou no máximo duas serras

b) Modelo “Médio-Grande” Porte - São as serrarias que possuem 3-4 serras ou mais. Podem estar ou não ligadas a empresas de extração, ou seja, o dono da pedreira possui também a serraria como parte da empresa. Entre estas encontram-se as mais dinâmicas, e as que buscaram por novas alternativas e tecnologias, tanto voltadas para a extração quanto para o beneficiamento, e que hoje despontam como definidoras para os novos modelos desenvolvidos no local. 


\subsection{Modelos Recentes}

a) Investimentos em Grupo - Empresas se juntam e em grupo tentam buscar soluções para problemas em comum e melhorias na qualidade do beneficiamento.

Embora existam várias associações de produtores, devido a diferenças de opiniões internas, nenhuma ação efetiva, generalizada e com fins práticos tem sido tomada.

Sendo assim, resultados concretos somente são obtidos por pequenos grupos de empresas que conseguem adaptar as suas necessidades individuais, às soluções partilhadas em comum pelo grupo.

b) Investimentos individuais - Empresas que individualmente buscam inovações quanto ao beneficiamento.

Os modelos identificados acima, foram resumidos na tabela apresentada a seguir:

\begin{tabular}{|l|l|}
\multicolumn{1}{|c|}{ Extração } & \multicolumn{1}{|c|}{ Beneficiamento } \\
\hline Primeiros modelos: & Primeiros modelos: \\
$\begin{array}{l}\text { a) O Proprietário do terreno extrai as rochas } \\
\text { b) O Proprietário do terreno é o } \\
\text { titular do registro porém aloca parte } \\
\text { ou integralmente a frente de lavra. }\end{array}$ & $\begin{array}{l}\text { a) } \\
\text { bédio-Grande Porte } \\
\text { - Com pedreira própria } \\
\text { c) O Proprietário aloca integralmente } \\
\text { o "terreno" onde se desenvolve a } \\
\text { mineração. }\end{array}$ \\
\hline Modelos Recente: & \\
d) "Terceirização & Modelos Recente: \\
e) "Prestação de Serviço" & a) Investimentos em Grupos \\
\hline
\end{tabular}

Quadro de Classificação das empresas de mineração segundo modelos de atuação identificados no local. 
As classificações dos modelos expostos na tabela, tanto de exploração quanto de beneficiamento, foram apenas uma tentativa de entender melhor as relações comerciais e de serviço vigentes na região. E embora todas elas sejam próprios do local, são todas aparentemente legalizadas.

O que se tem, na verdade, é o surgimento de novas formas de desenvolver as atividades minerais, a partir da experiência comum; ou inovações individuais por parte de alguns empresários.

\section{Conclusões}

A grande variedade de tipos litológicos bem reservados, no município de Santo Antônio de Pádua, , é fator fundamental para colocar o município em posição de destaque, no estado, como Parque Produtor de Rochas ornamentais.

O município apresenta uma oferta de mão-de-obra capaz de suprir as necessidades exigidas pela atividade .

É certo que se faz necessário um maior investimento em capacitação de pessoal, tanto no que diz respeito ao empregado das frentes de lavra e beneficiamento, quanto do próprio empresário, que na grande maioria dos casos demonstra desconhecer qualquer técnica administrativa mais complexa, além daquelas adquiridas no transcorrer das atividades do próprio dia-a-dia.

Chama-se bastante atenção para a necessidade que há de união entre os pequenos produtores, para que juntos busquem por melhorias técnicas que minimizem as perdas aumentanto assim a margem de lucro; bem como uma central de vendas que busque por melhores preços e pesquisem a procedência dos compradores de forma a evitar os “calotes”, muito comum entre os empresário de médio a pequeno porte. 


\section{Fluxograma de Beneficiamento}

\section{Etapas básicas de beneficiamento normalmente utilizado}

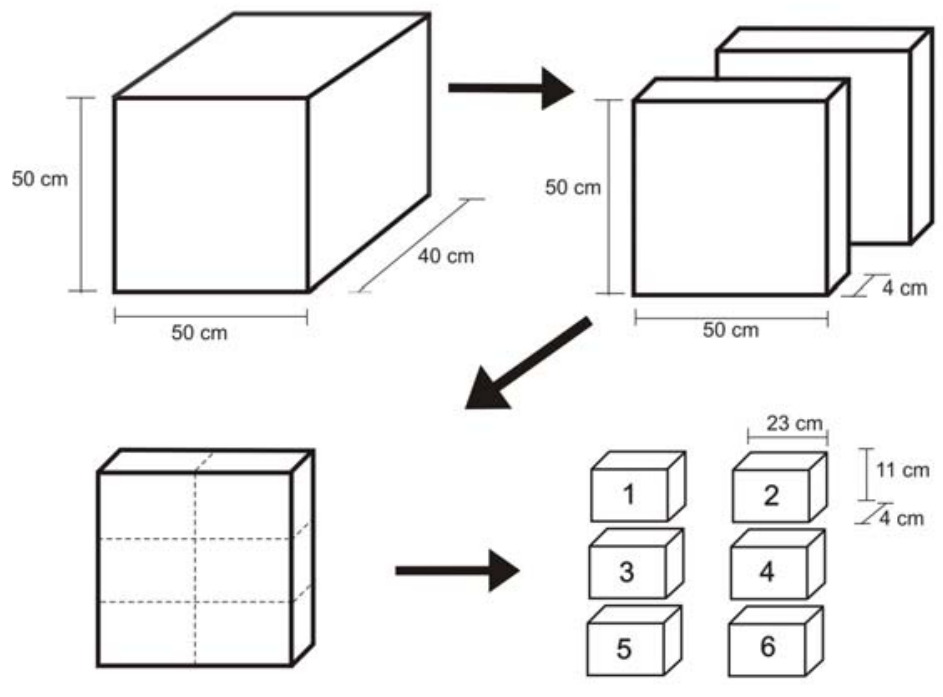

Fluxograma básico no beneficiamento normalmente utilizado. Os blocos de 50x50x40(cm), são desplacados ainda nas frentes de lavra em "lajes brutas" de 50x50x4cm aproximadamente, que por sua vez são serradas em lajes de aproximadamente $23 \times 11 \times 4 \mathrm{~cm}$, estas então são entregues aos rachadores, que por percussão manual dão o acabamento final abrindo os blocos e finalmente produzindo as lajinhas de $23 \mathrm{x} 11 \mathrm{x}(1,2-1,7) \mathrm{cm}$. 


\section{Referências}

CIDE . 1996. (Centro de Informação e Dados do Rio de Janeiro). Anuário Estatístico do Estado do Rio de Janeiro.

CIDE. 1998. (Centro de Informação e Dados do Rio de Janeiro).

Anuário Estatístico do Estado do Rio de Janeiro- (http://www.cide.gov.br)

Coelho, C. M \& Margueron, C. 1997. Plano de Ação para o Setor de Rochas

Ornamentais do Rio de Janeiro (IGEO/CCMN/UFRJ).

CPRM (Departamento de Pesquisa de Recursos Minerais) e DNPM (Departamento Nacional de produção Mineral).1976. Projeto Vale do Paraíba - Relatório Final, Rio de Janeiro.

DNPM (DepartamentoNacional de produção Mineral) - Ministério das Minas e Energia). Perfil Analítico dos Mármores e Granito. Boletim N³8 - Vol. I.

DRM- RJ (Departamento de Recursos Minerais do Estado do Rio de Janeiro). Estudo do Parque Produtor de Brita da Região Metropolitana do Estado do Rio de Janeiro. Vol. I ao Vol X.

DRM- RJ (Departamento de Recursos Minerais do Estado do Rio de Janeiro). Projeto Rochas Ornamentais. 1992. A Rocha Ornamental de Santo Antônio de Pádua - Diagnóstico Preliminar, julho.

DRM- RJ (Departamento de Recursos Minerais do Estado do Rio de Janeiro). 1993. Projeto Rochas Ornamentais - Relatório de Atividade em 1992, março.

Guttmann, A. M. 1999. Levantamento Econômico e Ambiental em Pedreiras na Serra do Bonfim. Município de Santo Antônio de Pádua - RJ, novembro (IGEO/CCMN/UFRJ).

INT - Dep. de Materiais Minerais (Instituto Nacional de Tecnologia).1999. Caracterização Tecnológicas de Pedras Miracema e Madeira (alguma amostras) - Relatório Preliminar, projeto RETECMIN, sob a Coord. do Eng. José Carlos da Rocha (Phd), julho.

Oliveira, T. M.A. 1998. Avaliação Econômica da Extração de Rochas Ornamentais do Município de Santo Antônio de Pádua - RJ, março (IGEO/ CCMN/UFRJ). 